\title{
Positive Role of Salicylic Acid and Trichoderma on the Enhancement of Systemic Acquired Resistance (SAR) and Induced Systemic Resistance (ISR) in Maize - Exserohilum turcicum Pathosystem under Greenhouse Condition
}

\author{
Geeta $^{1 *}$, D.S. Aswathanarayana ${ }^{1}$, M.K. Naik ${ }^{2}$, Mallikarjun Kenganal ${ }^{1}$, \\ Prakash H. Kuchanur ${ }^{3}$ and R.V. Beladadi ${ }^{4}$ \\ ${ }^{1}$ Department of Plant Pathology, ${ }^{4}$ Department of Biochemistry, College of Agriculture, \\ University of Agricultural Sciences, Raichur-584104, Karnataka, India \\ ${ }^{2}$ Department of Plant Pathology, University of Agricultural and Horticultural Sciences, \\ Shivamogga, Karnataka, India \\ ${ }^{3}$ Department of Genetics and Plant Breeding, College of Agriculture, Bheemarayanagudi, \\ Karnataka, India \\ *Corresponding author
}

\begin{tabular}{|c|}
\hline Keywords \\
\hline $\begin{array}{l}\text { Maize, Exserohilum } \\
\text { turcicum, Induced } \\
\text { Systemic Resistance } \\
\text { (ISR), Systemic Acquired } \\
\text { Resistance (SAR) }\end{array}$ \\
\hline Article Info \\
\hline $\begin{array}{l}\text { Accepted: } \\
12 \text { September } 2018 \\
\text { Available Online: } \\
10 \text { October } 2018\end{array}$ \\
\hline
\end{tabular}

A B S T R A C T

Systemically acquired resistance (SAR) and Induced systemic resistance (ISR) agents can trigger host system to produce phenolic compounds, PR proteins, sugars which impart resistance in plants against invading pathogens. The application of different concentrations of salicylic acid and Trichoderma viride (Tri-25) viz., single inoculation, combination inoculation with challenge inoculation of Exserohilum turcicum on the enhancement of growth and management of disease with special emphasis to ISR and SAR against turcicum leaf blight disease. Total phenols content were positively regulated in both the inbred lines treated with $T$. viride and salicylic acid in combination. In ISR, the proteins content increased from the $7^{\text {th }}$ day of sampling and in SAR, the protein contents were increased from $24 \mathrm{hr}$ to $72 \mathrm{hr}$ in all the treatments. The higher amount of total sugars was noticed in resistant as compared to susceptible inbred line. Total sugars, reducing sugars and non-reducing sugars were less in pathogen inoculated maize inbred lines. Chlorophyll content maximum in resistant compared to susceptible inbred line and increased over a period of time in all the treatments except in pathogen inoculation. Combination of salicylic acid and $T$. viride has quite long term influence on enhancement of biochemical components in host plant. 


\section{Introduction}

Maize (Zea mays L.) is an important coarse cereal and third major crop of the India after rice and wheat. It is cultivated in tropics, subtropics and temperate regions under irrigated and rainfed conditions. Maize crop which provides more nutrients for humans and animals than any other cereals and the same is grown across a wide range in North Eastern Karnataka. Turcicum leaf blight disease of maize is caused by Exserohilum turcicum one of the ubiquitous and most destructive fungal disease of maize. TLB is considered to be one of the most devastating foliar diseases in Karnataka resulting in reduction of grain yield by 28 to 91 per cent (Pandurangegowda, 1991 and Harlapur et al., 2000). Now-a-days, maize production management strategies in mainly focus on chemical amelioration, including, the use of synthetic chemical fertilizers and pesticides at high rates to enhance the per hectare yield of crop. The enormous use of synthetic chemicals is too expensive and also leads to environmental hazards. In this context, plant growth promotion by free living, beneficial soil microorganisms, as a biological approach, might be an alternative strategy to overcome the biological and environmental hazards posed by the persistent use of synthetic chemicals and application of biocontrol agents for crop protection is very significant as it has several advantages such as possibility of multiple pathogen suppression, low cost and promotion of soil fertility. It is evident that several natural and induced defence mechanisms operate in host plants against different diseases. One such defence mechanism is the presence of certain compounds inhibitory to the pathogen. Sometimes, the host plant is induced to synthesize these compounds on infection. Analysis of biochemicals in selected resistant and susceptible genotypes was carried out at different intervals of crop growth stages to understand their role in resistance / susceptibility to turcicum leaf blight pathogen. Trichoderma strains protect plants from pathogen attack by strengthening the epidermal and cortical cell walls using a deposition of callose, lignin and phenolics (Shyamala and Sivakumaar, 2012). Further, biocontrol strains stimulate the activities of defence enzymes and total phenols in plants that could be involved in synthesis of phytoalexins. Salicylic acid treated plants also showed an increase in total phenols content in resistant inbred lines may be due to more sugar as it acts as precursor for synthesis of phenolics (Shyamala and Sivakumaar, 2012). Phenol content and its enhancement during disease progress were least in susceptible inbred line. However, there were no earlier reports regarding the development and use of ISR and SAR in combination treatment at 0 day, 7 day, 14 day and 21 day in case of ISR and $0 \mathrm{hr}, 24 \mathrm{hr}, 48 \mathrm{hr}$ and $72 \mathrm{hr}$ in case SAR in both resistant and susceptible. Hence, the present research work has been undertaken with an aim to exploit the positive role of salicylic acid and Trichoderma on the enhancement of Induced systemic resistance (ISR) and Systemic acquired resistance (SAR) in Maize - Exserohilum turcicum pathosystem under greenhouse condition on plant growth stimulation.

\section{Materials and Methods}

Effect of SAR and ISR agents against $E$. turcicum under in vivo. The seeds of resistance and susceptible maize inbred lines were first soaked in SAR chemical salicylic acid and ISR agent Trichoderma viride (Tri-26) respectively at $10 \mathrm{mM}$ and $1 \times 10^{6} \mathrm{cfu} / \mathrm{g}$ concentration for 18 hours followed by shade dry for 30 minutes. The seeds were sown in polythene covers containing sterilized soil with three replications. The pathogen $E$. turcicum was challenge inoculated at seven days after emergence of seedlings. The leaf samples were drawn on the day of challenge 
inoculation followed by 24 hours, 48 hours and 72 hours after challenge inoculation in case of SAR studies. Whereas leaf samples were drawn on the day of challenge inoculation followed by 7,14 and 21 days after challenge inoculation in case of ISR and was subjected for biochemical analysis.

\section{Extraction of plant tissues in alcohol}

The samples required for biochemical analysis were extracted from healthy and challenge inoculated leaves from both resistant and susceptible maize inbred lines using 80 per cent alcohol as per the standard procedure mentioned below.

Five grams of leaf tissue was weighed and make into small pieces and grind with the help of pestel and mortar in $20 \mathrm{ml} 80$ per cent alcohol. Then, it was passed through double layered muslin cloth. Again grind thoroughly in a pestle and mortar with $20 \mathrm{ml} 80$ per cent alcohol and it was passed through muslin cloth. The above procedure was repeated. The filtrate was pooled and filtered through Whatman No. 41 filter paper and the extract made up to $50 \mathrm{ml}$ final volume. Then the extract was stored in a refrigerator at $4{ }^{0} \mathrm{C}$. This alcoholic extract of the tissue was used for estimation of reducing sugars, non reducing sugars, phenols etc.

The plant tissues contain a large number of phenolic compounds. The total phenols present in plant samples were estimated by following Folin Ciocalteau reagent (FCR) method (Bray and Thorpe, 1954). Protein estimation was done by following the procedure of Lowry et al., (1951). Bovine serum albumin was used as the standard. Sugars are precursors for synthesis of phenols, phytoalexins, lignin and callose. Hence, they play an important role in defense mechanism of plants. The total sugars content was estimated after acid hydrolysis of non- reducing to reducing sugars by following Nelson's modification of Somogyi's method (Nelson, 1944).

\section{Results and Discussion}

\section{Total phenols}

Studies on biochemical changes were carried out in both resistant (HS-2) and susceptible (CM-202) maize inbred lines at 0, $24 \mathrm{hrs}, 48$ hrs and $72 \mathrm{hrs}$ after pathogen inoculation as influenced by inducing chemicals of SAR and $0,7,14$ and 21day after pathogen inoculation in ISR inducing bioagent. The biochemical components present in plant imparts resistance against several diseases. Among them phenolics have been found to play an important role in determining resistance or susceptibility of a host to parasitic infection.

The both resistant (HS-2) and susceptible (CM-202) inbred lines showed significant difference in total phenols content with respect to different days of crop growth. The seeds of both resistant and susceptible maize inbred lines were treated with one effective ISR agent T. viride (Tri-25) and SAR chemical Salicylic acid which was based on in vitro study. The results revealed that, phenols content increased after pathogen infection in both resistant and susceptible inbred lines. Initially phenols content was high in susceptible inbred line than that of resistant inbred line, except in water soaking - pathogen inoculation $(0.88$ and $0.56 \mathrm{mg} / \mathrm{g})$ and control treatment $(1.20$ and $1.11 \mathrm{mg} / \mathrm{g}$ ), respectively.

In ISR, after inoculation of the pathogen $E$. turcicum to maize inbred lines, the phenols content increased up to $7^{\text {th }}$ day after inoculation, after that it showed increasing in some treatments and also showed decreasing trend in some of the treatments (Trichoderma alone as well as in water soaking - pathogen inoculation). Among the seven treatments, the 
maximum content of total phenol was recorded in resistant $(1.20 \mathrm{mg} / \mathrm{g})$ and in susceptible $(1.11 \mathrm{mg} / \mathrm{g})$ lines of control treatment at the initial sampling immediately after inoculation. The phenols content was increased from the $7^{\text {th }}$ day of sampling and found maximum content of total phenols in resistant $(1.89 \mathrm{mg} / \mathrm{g})$ and susceptible (1.71 $\mathrm{mg} / \mathrm{g}$ ) inbred lines recorded in $T$. viride (Tri25) alone and $T$. viride (Tri-25) - challenge inoculation treatments, respectively. At the end $\left(21^{\text {st }}\right.$ day) of sampling period, the maximum total phenols activity was observed in resistant $(1.89 \mathrm{mg} / \mathrm{g})$ line and susceptible line (1.63) of salicylic acid - T. viride (Tri-25) with pathogen inoculation treatment. Similarly at initial sampling minimum content of total phenols were recorded in resistant $(0.23 \mathrm{mg} / \mathrm{g})$ and susceptible $(0.40 \mathrm{mg} / \mathrm{g})$ line treated with T. viride (Tri-25) - water spray treatment. At the end $\left(21^{\text {st }}\right.$ day) of sampling period, minimum content of phenols were observed in resistant $(0.50 \mathrm{mg} / \mathrm{g})$ and susceptible $(0.23$ $\mathrm{mg} / \mathrm{g}$ ) lines in water soaking - pathogen inoculation treatment (Fig. 1).

In SAR, at same day after challenge inoculation, phenols content was low in both resistant and susceptible inbred lines. Phenols content was increased from $24 \mathrm{hr}$ after challange inoculation in both resistant and susceptible. After inoculation of pathogen $E$. turcicum significantly increased phenols activity in all the treatments. The maximum content of total phenols were recorded in resistant $(0.77 \mathrm{mg} / \mathrm{g})$ and in susceptible $(0.68$ $\mathrm{mg} / \mathrm{g}$ ) lines treated with salicylic acid - $T$. viride (Tri-25) followed by pathogen inoculation and control treatments, respectively at the initial sampling immediately after inoculation. The phenols increased from the $24 \mathrm{hr}$ after challenge inoculation, maximum content of total phenol in resistant $(0.90 \mathrm{mg} / \mathrm{g})$ and in susceptible $(1.28 \mathrm{mg} / \mathrm{g})$ lines was recorded in salicylic acid - challenge inoculation and salicylic acid alone treatment, respectively. At the end (72 hr) of sampling period, the maximum total phenols activity was noticed in resistant (1.89 $\mathrm{mg} / \mathrm{g}$ ) and in susceptible (1.33) lines in salicylic acid molecule alone treatment followed by salicylic acid - water spray treatments which were significantly superior over other treatments. Similarly at the end (72 hr) of sampling period minimum content of phenols was recorded in resistant $(0.47 \mathrm{mg} / \mathrm{g})$ and in susceptible $(0.41 \mathrm{mg} / \mathrm{g})$ inbred lines in salicylic acid - challenge inoculation and water soaking - pathogen inoculation treatments respectively (Fig. 2).

The phenol contents were possitively regulated in both the lines treated with salicylic acid - T. viride (Tri-25) followed by pathogen inoculation over a period of time but it was down regulated in both the lines inoculated by E. turcicum.

The study of disease resistance in maize plants treated with $T$. viride (Tri-25) and salicylic acid revealed the higher activity of defence related total phenols against maize turcicum leaf blight. Application of $T$. viride and salicylic acid in combination with each other significantly influenced the phenols activity. Similar biochemical changes are also noticed by Natheer et al., (2013), Bisen et al., (2015), Jagadeesh (2013) and Rashmi (2015).

\section{Total proteins}

The total proteins content varied significantly among the inbred lines of resistant (HS-2) and susceptible (CM-202). Comparatively less proteins content were observed after pathogen infection in the susceptible inbred line than that of resistant inbred line.

In ISR, the results revealed that, the maximum content of total proteins were recorded in resistant $(0.96 \mathrm{mg} / \mathrm{g})$ and in susceptible $(0.90$ $\mathrm{mg} / \mathrm{g}$ ) lines treated with $T$. viride (Tri-25) 
alone at the times of initial sampling. The proteins contents increased from the $7^{\text {th }}$ day of sampling, maximum content of total proteins were recorded in resistant $(1.10 \mathrm{mg} / \mathrm{g})$ and in susceptible $(0.98 \mathrm{mg} / \mathrm{g})$ in $T$. viride (Tri-25) alone treatment. At the end $\left(21^{\text {st }}\right.$ day) of sampling period, the maximum total proteins activity was noticed in resistant $(2.31 \mathrm{mg} / \mathrm{g})$ and in susceptible $(2.30 \mathrm{mg} / \mathrm{g})$ lines in salicylic acid - T. viride (Tri-25) with pathogen inoculation treatment. Similarly minimum content of total proteins were observed in resistant $(0.13 \mathrm{mg} / \mathrm{g})$ and in susceptible $(0.11 \mathrm{mg} / \mathrm{g})$ lines treated with water soaking - pathogen inoculation treatment at the initial sampling. At the end $\left(21^{\text {st }}\right.$ day) of sampling period minimum content of total proteins were recorded in resistant $(0.33 \mathrm{mg} / \mathrm{g})$ and in susceptible $(0.51$ $\mathrm{mg} / \mathrm{g}$ ) lines in water soaking - pathogen inoculation treatment (Fig. 3).

Among all the treatments, significantly more proteins were recorded in both the inbred lines treated with salicylic acid - $T$. viride (Tri-25) with pathogen inoculation followed by $T$. viride (Tri-25) - water spray and $T$. viride (Tri25) - challenge inoculation treatments, respectively.

Interestingly it has been observed that there was four folds increase in protein contents from initial sampling at 7 days of challenge inoculation in $T$. viride (Tri-25) - challenge inoculation followed by $T$. viride (Tri-25) water spray treatments in both the lines.

In SAR inducing treatments, the maximum content of total proteins were recorded in resistant $(0.55 \mathrm{mg} / \mathrm{g})$ and susceptible $(0.50$ $\mathrm{mg} / \mathrm{g}$ ) lines in water soaking - pathogen inoculation treatment at initial sampling immediately after inoculation which is significantly superior over the treatments. The proteins increased from the $24 \mathrm{hr}$ of sampling with maximum content in resistant (1.95 $\mathrm{mg} / \mathrm{g})$ and susceptible $(1.90 \mathrm{mg} / \mathrm{g})$ lines in water soaking - pathogen inoculation. At the end (72 hr) of sampling period, the maximum total proteins activity was noticed in resistant (2.32 $\mathrm{mg} / \mathrm{g})$ and susceptible (2.32) lines treated with salicylic acid - $T$. viride (Tri-25) with pathogen inoculation and salicylic acid water spray treatments, respectively. Similarly at the end $(72 \mathrm{hrs})$ of sampling period minimum content of proteins were observed in resistant $(0.98 \mathrm{mg} / \mathrm{g})$ and susceptible $(0.78$ $\mathrm{mg} / \mathrm{g}$ ) lines in pathogen inoculation treatment. It has been observed that, there was five fold increase in protein contents from $24 \mathrm{hr}$ to 48 $\mathrm{hr}$ in both lines treated with salicylic acid challenge inoculation, salicylic acid - water spray and salicylic acid alone treatments. There after increase was quite slow. The protein contents were increased from $24 \mathrm{hr}$ to $72 \mathrm{hr}$ in all the treatments except in both the lines treated with water soaking - pathogen inoculations at $48 \mathrm{hrs}$ on words (Fig. 4).

The infection with pathogen resulted in reduction of the total concentration of nitrogen in plant tissue. Staples and Stahmann (1964) reported that infection of bean leaves with rust fungus resulted in formation of new protein accompanied by decrease in one host protein. These results are similar to the findings of Pradeepkumar (2005), Nagaveni (2005), Sriram et al., (2009), Jagadeesh (2013) and Bisen et al., (2015). In contrary to the present findings, Arjunan et al., (1976) observed that protein content in healthy and infected leaves was 0.24 and 0.02 per cent in ten day old plants, respectively in sorghum infected by $H$. turcicum.

\section{Total sugars}

In ISR studies the results revealed that, variation in total sugars content across both the resistant and susceptible maize inbred lines and also based on duration of crop growth. However, maximum total sugars content was 
observed in resistant inbred line in the treatment with salicylic acid - $T$. viride (Tri$25)$ with pathogen inoculation, at the same day of pathogen inoculation $(2.15 \mathrm{mg} / \mathrm{g})$ and at the end it was increased to $3.55 \mathrm{mg} / \mathrm{g}$ (21 days after inoculation). Increased trend was also observed in susceptible line from same day of inoculation $(1.68 \mathrm{mg} / \mathrm{g})$ to 21 days after inoculation $(2.85 \mathrm{mg} / \mathrm{g})$ in the same treatment compared to the control. The next best treatment was observed in both inbred lines treated with $T$. viride (Tri-25) - water spray $(0.74 \mathrm{mg} / \mathrm{g})$ and it was increased to $3.68 \mathrm{mg} / \mathrm{g}$ at initial stage and 21 days after inoculation, respectively in resistant line. In susceptible line total sugars content was found initially as $0.78 \mathrm{mg} / \mathrm{g}$ and it was increased to $3.32 \mathrm{mg} / \mathrm{g}$ at the end of sampling. Least amount of total sugars were observed in water soaking pathogen inoculation treatment both in resistant and susceptible lines from same day of inoculation to 21 days after inoculation and found decreased $(0.87,1.11 \mathrm{mg} / \mathrm{g}$ and 0.66 and 0.32 ) respectively. The total sugars contents were enhanced nearly three to four folds in Trichoderma (Tri-25) - water spray and Trichoderma (Tri-25) alone treatment compared to pathogen inoculation treatment (Fig. 5).

The results of reducing sugars content was also varied across the inbred lines and based on duration of crop growth. The maximum reducing sugars content was noticed in salicylic acid - $T$. viride (Tri-25) with pathogen inoculation in both resistant $(0.93$ $\mathrm{mg} / \mathrm{g})$ and susceptible $(0.59 \mathrm{mg} / \mathrm{g})$ lines at same day of inoculation and increased at the end $(1.99 \mathrm{mg} / \mathrm{g})$ and $(1.62 \mathrm{mg} / \mathrm{g})$ of sampling, respectively. Least reducing sugars were recorded in water soaking - pathogen inoculation treatment at same day of inoculation in resistant $(0.11 \mathrm{mg} / \mathrm{g})$ line and in susceptible line noticed $0.11 \mathrm{mg} / \mathrm{g}$ in pathogen inoculation treatment. At the end of sampling reducing sugars were $0.11 \mathrm{mg} / \mathrm{g}$ and 0.10 $\mathrm{mg} / \mathrm{g}$ was observed in both the inbred lines respectively in water soaking - pathogen inoculation treatment (Fig. 7).

In case of non-reducing sugars, the content was varied across the inbred lines. The maximum non reducing sugars content was found in same treatment same as that of reducing sugars salicylic acid - $T$. viride (Tri$25)$ with pathogen inoculation. At same day of inoculation observed $1.22 \mathrm{mg} / \mathrm{g}$ and $1.09 \mathrm{mg} / \mathrm{g}$ in resistant and susceptible lines respectively. At the end of $21^{\text {st }}$ day of inoculation, observed highest non reducing sugar in resistant (1.79 $\mathrm{mg} / \mathrm{g})$ and susceptible $(1.77 \mathrm{mg} / \mathrm{g})$ inbred lines was treated with Trichoderma (Tri-25) - water spray treatment.

Least non reducing sugar content was observed in pathogen inoculation treatment same day of inoculation in resistant $(0.22$ $\mathrm{mg} / \mathrm{g})$ and susceptible $(0.11 \mathrm{mg} / \mathrm{g})$ lines. Whereas at the end of $21^{\text {st }}$ day of inoculation least non reducing sugar was noticed in $T$. viride (Tri-25) alone in resistant $(0.18 \mathrm{mg} / \mathrm{g})$, but $0.22 \mathrm{mg} / \mathrm{g}$ non reducing sugar were noticed in susceptible inbred line treated with water soaking - pathogen inoculation. However, reducing and non-reducing sugars were found quite high in resistant inbred line compared to susceptible line (Fig. 7).

In $\mathrm{SAR}$, the maximum content of total sugars were noticed in resistant $(2.72 \mathrm{mg} / \mathrm{g})$ and in susceptible $(2.27 \mathrm{mg} / \mathrm{g})$ in salicylic acid alone treatment at the time of initial sampling immediately. The sugars increased upto $24 \mathrm{hr}$ of sampling period. Maximum content of total sugar in resistant $(2.87 \mathrm{mg} / \mathrm{g})$ and susceptible $(2.99 \mathrm{mg} / \mathrm{g})$ inbred lines in the same treatment. At the end (72 hr) of sampling period, the maximum total sugars activity was noticed in resistant $(2.22 \mathrm{mg} / \mathrm{g})$ and susceptible (1.87 $\mathrm{mg} / \mathrm{g}$ ) lines in $T$. viride (Tri-25) - salicylic acid with pathogen inoculation and salicylic acid challenge inoculation respectively. 
Fig.1 Effect of ISR bioagents on induction of phenols content in maize inbred lines, challenge inoculation with E. turcicum

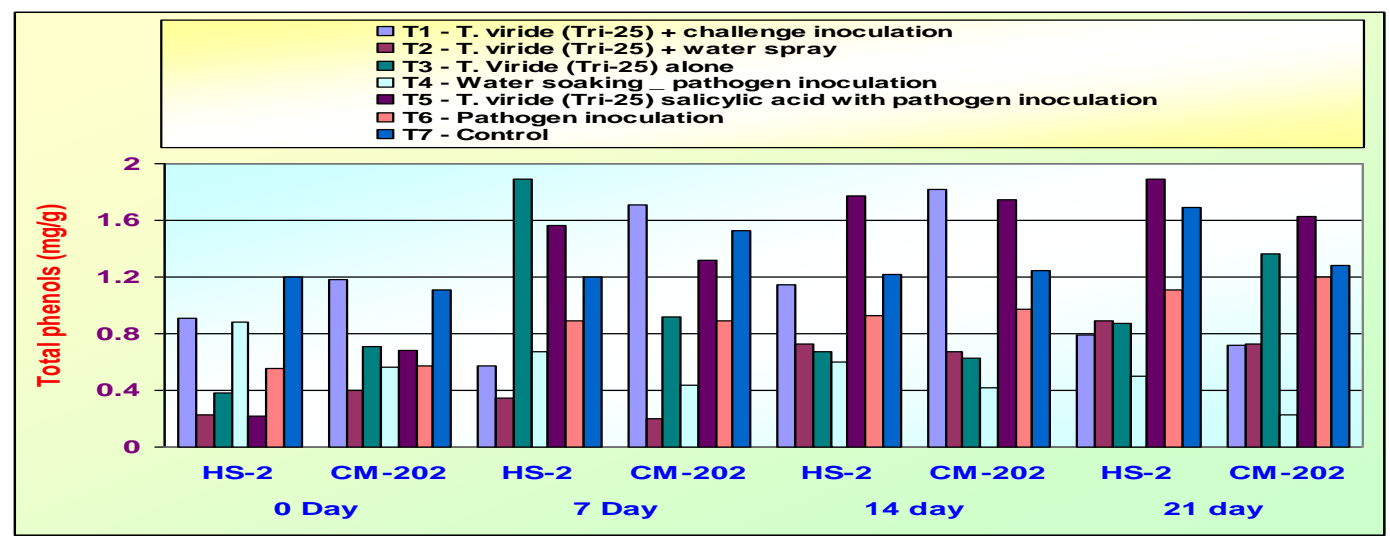

Fig.2 Effect of SAR inducing chemical on induction of phenols content in maize inbred lines, challenge inoculation with E. turcicum

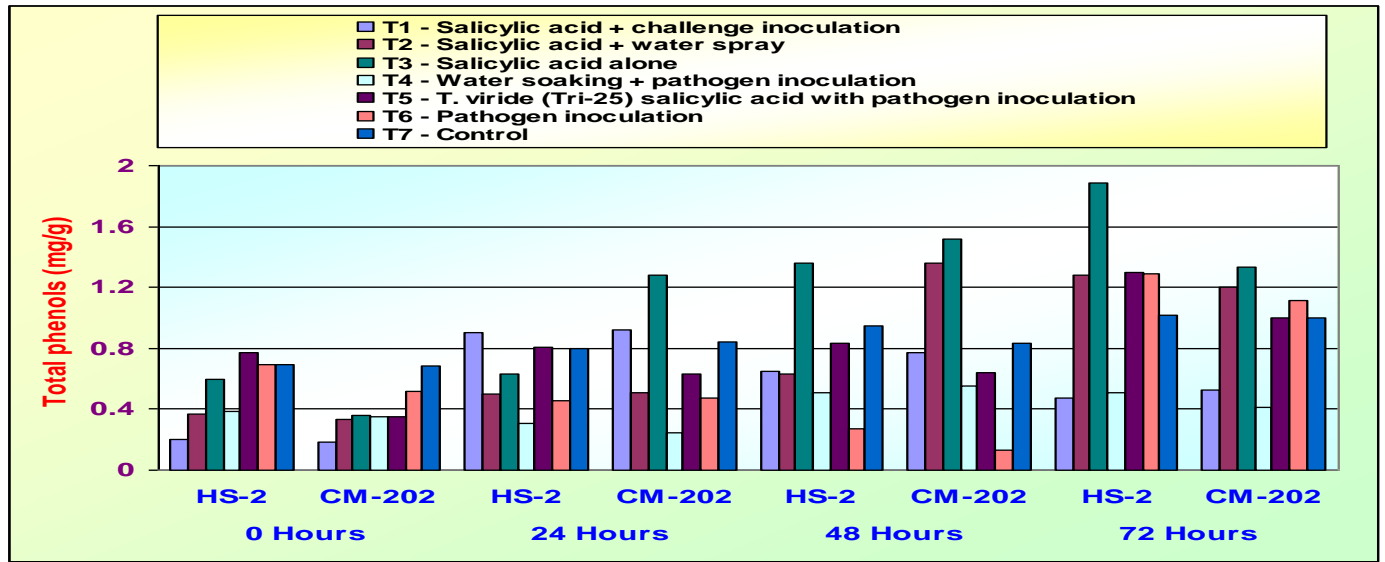

Fig.3 Effect of ISR inducing bioagent on induction of proteins content in maize inbred lines, challenge inoculation with E. turcicum

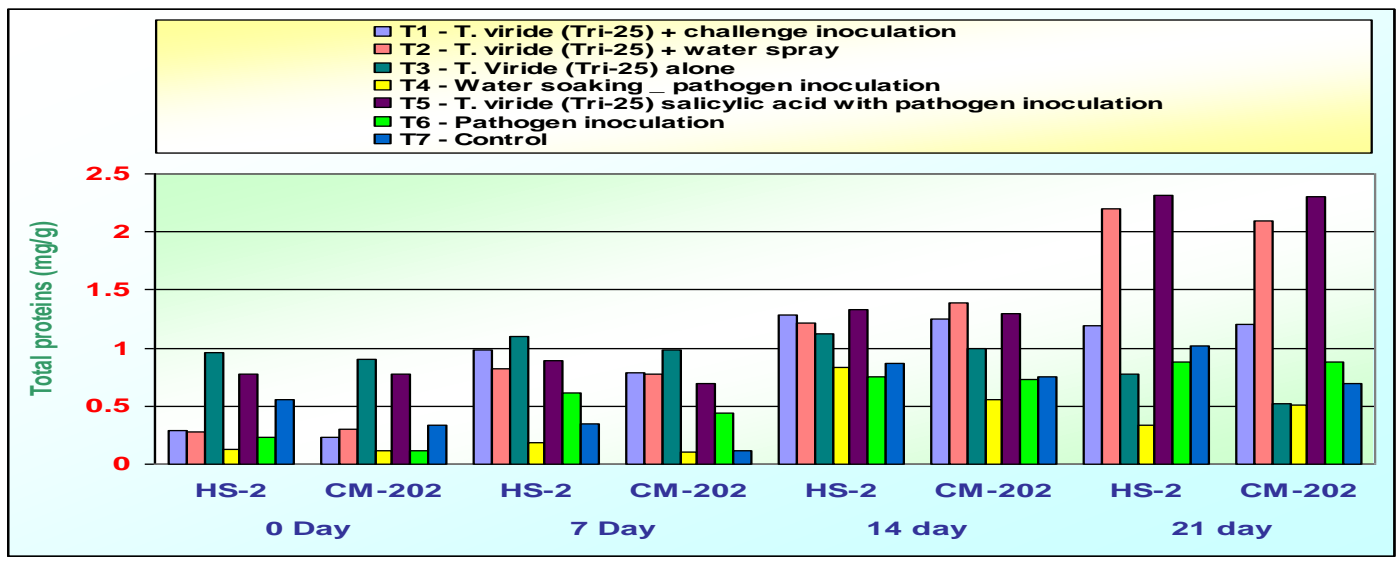


Fig.4 Effect of SAR inducing chemical on induction of proteins content in maize inbred lines, challenge inoculation with E. turcicum

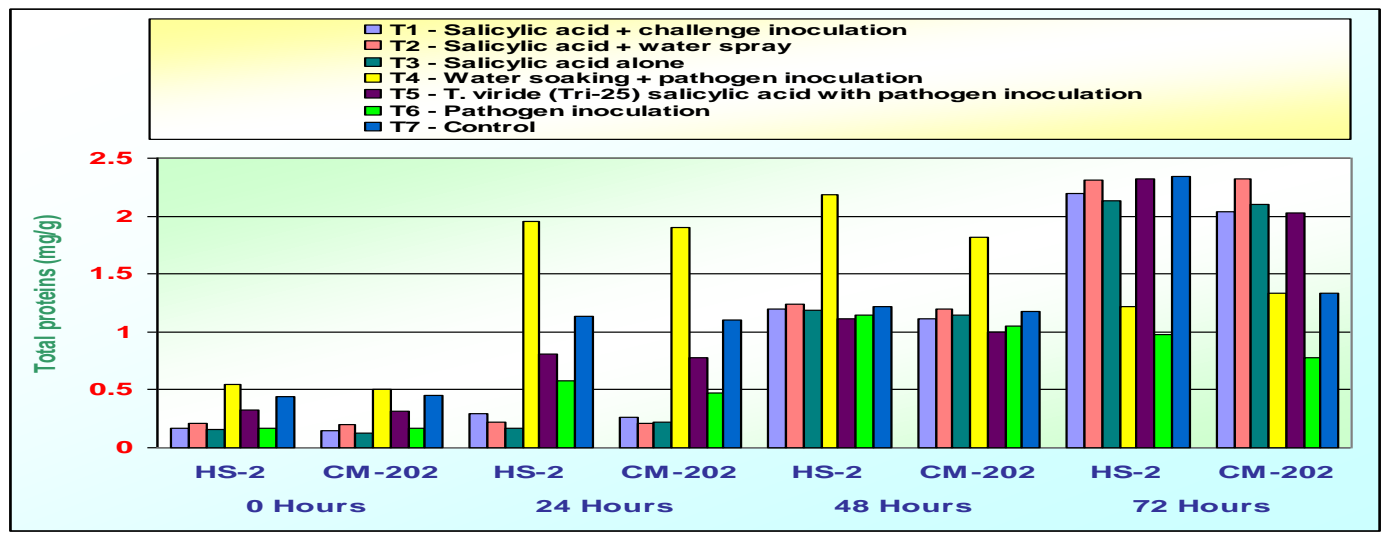

Fig.5 Effect of ISR inducing bioagent on induction of total sugars content in maize inbred lines, challenge inoculation with E. turcicum

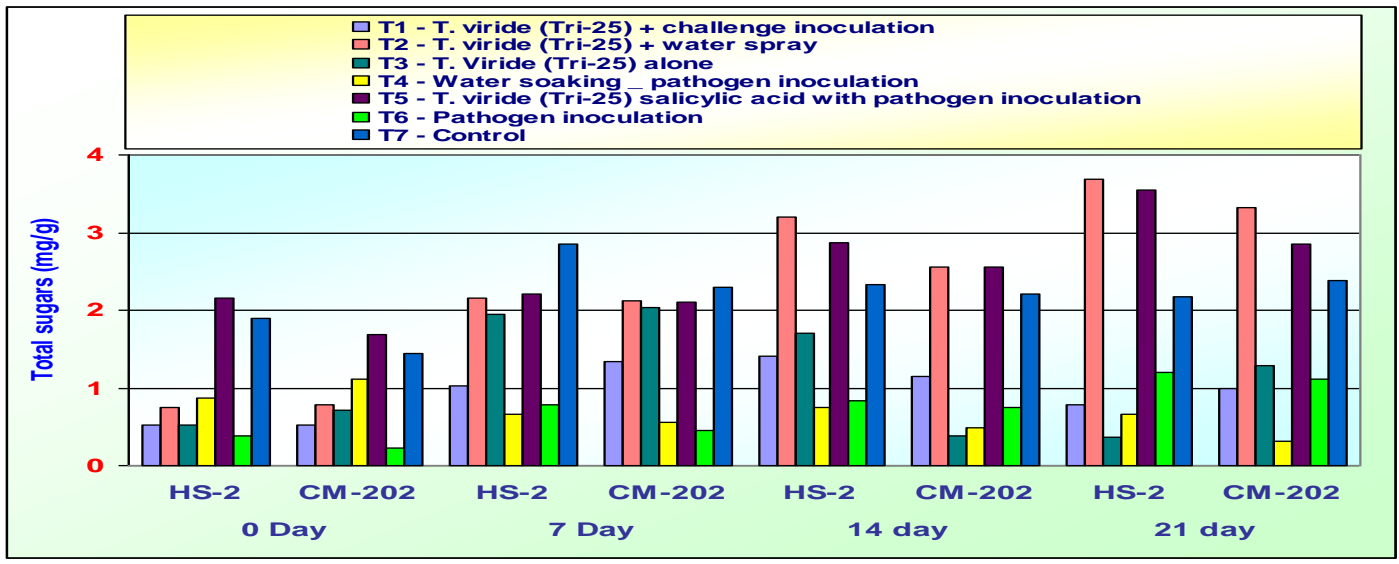

Fig.6 Effect of SAR inducing chemical on induction of total sugars content in maize inbred lines, challenge inoculation with E. turcicum

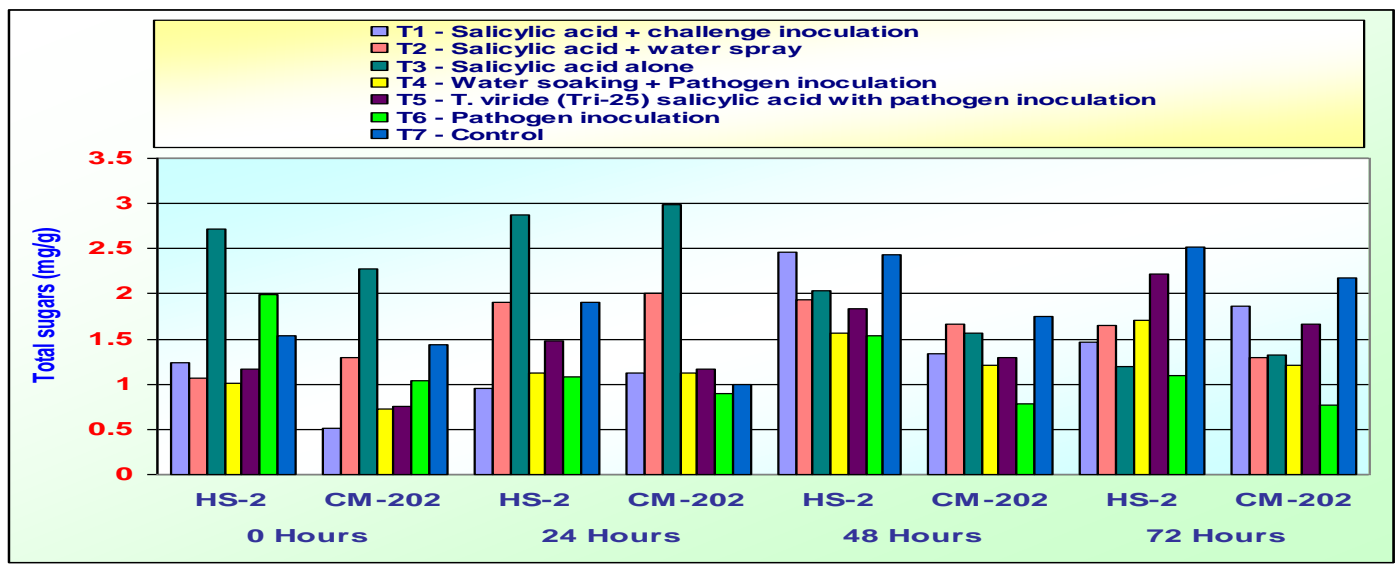


Fig.7 Effect of ISR inducing bioagent on induction of reducing and non-reducing sugars content in maize inbred lines, challenge inoculation with E. turcicum

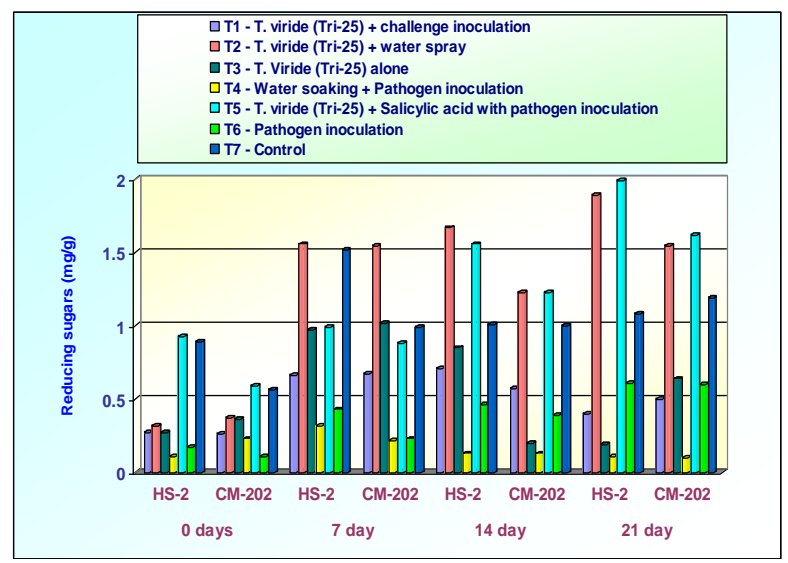

Reducing Sugars

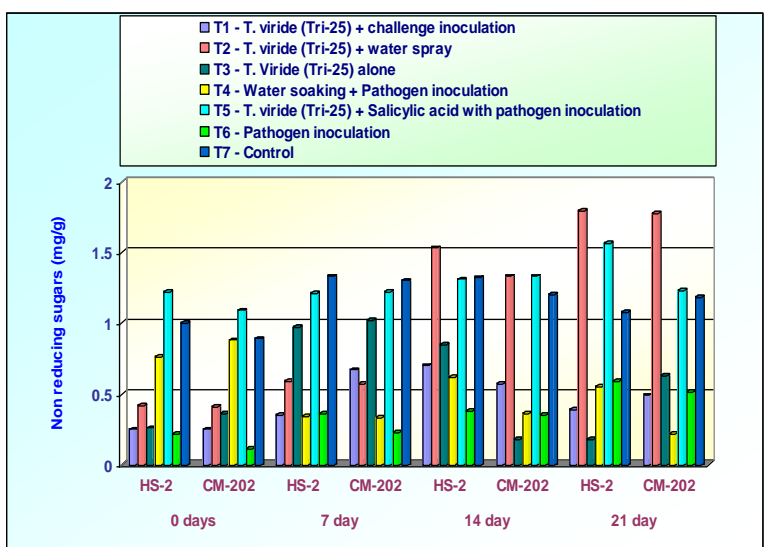

Non Reducing Sugars

Fig.8 Effect of SAR inducing chemical on induction of reducing and non-reducing sugars content in maize inbred lines, challenge inoculation with E. turcicum

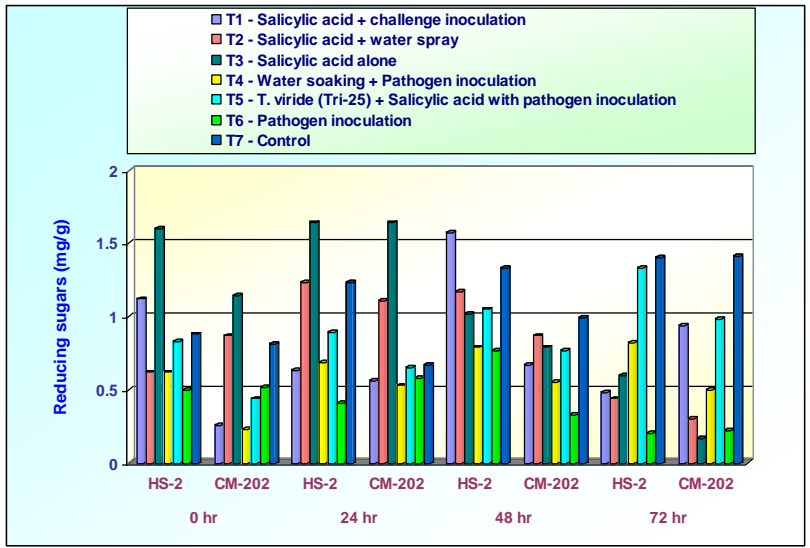

Reducing Sugars

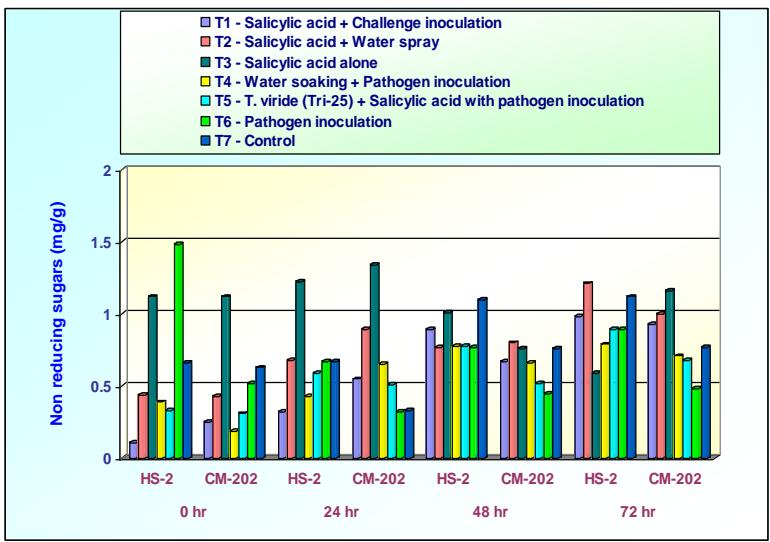

Non Reducing Sugars

Fig.9 Effect of ISR inducing bioagent on induction of chlorophyll content in resistant maize inbred line, challenge inoculation with E. turcicum

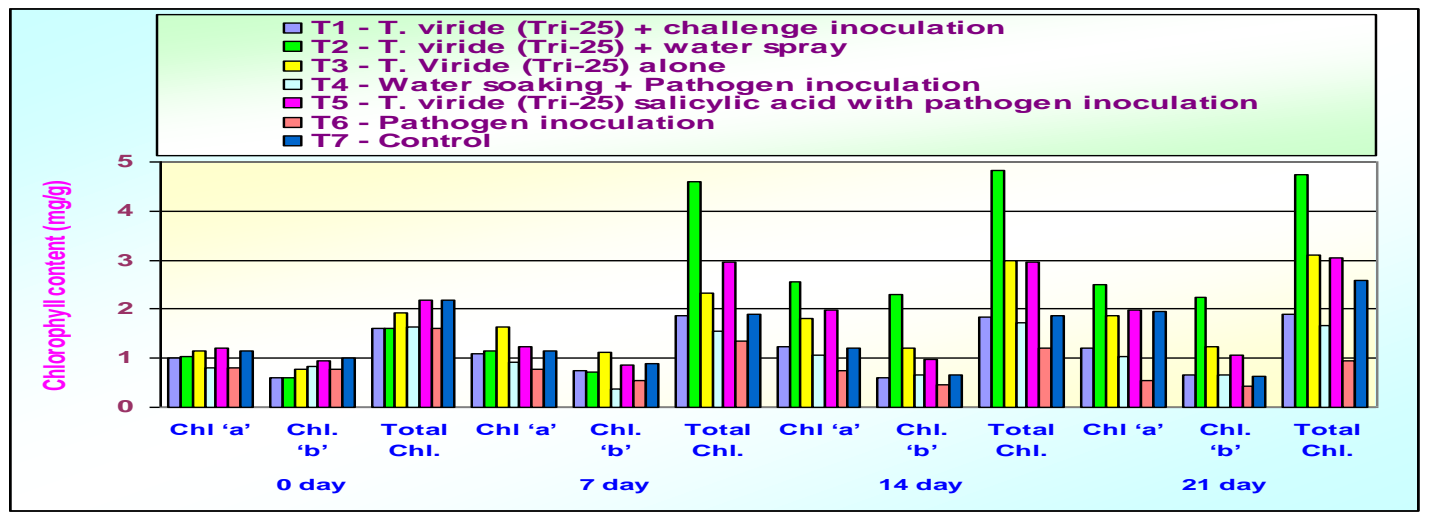


Fig.10 Effect of ISR inducing bioagent on induction of chlorophyll content in susceptible maize inbred line, challenge inoculation with E. turcicum

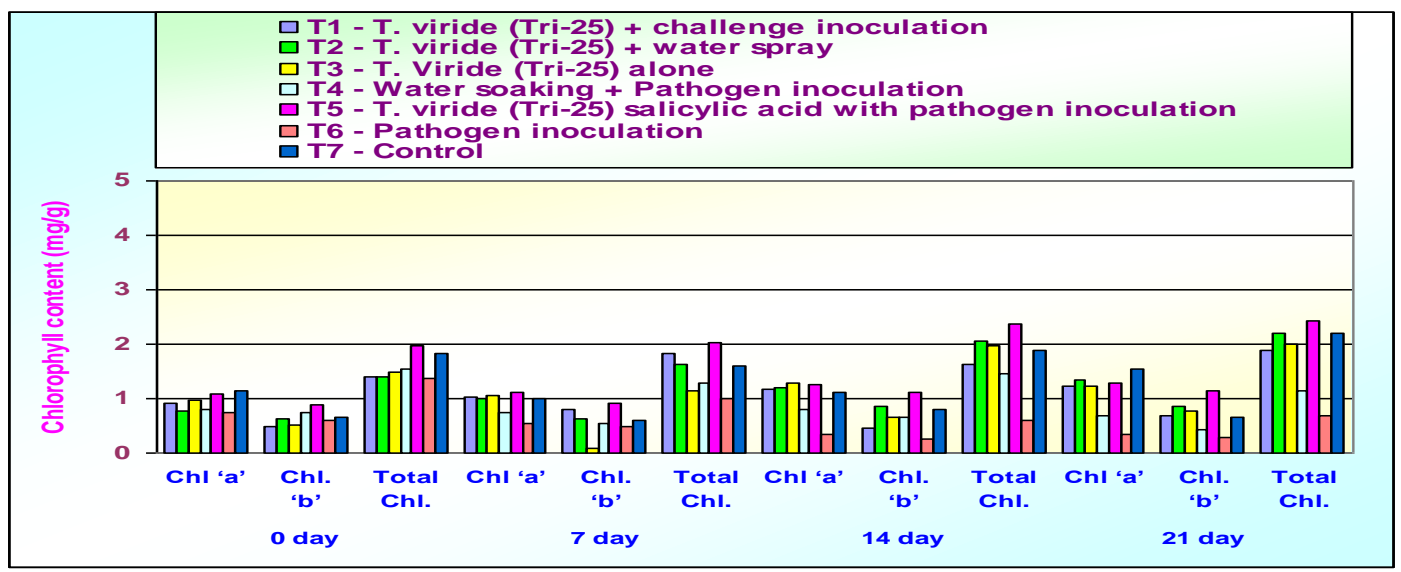

Fig.11 Effect of SAR inducing chemical on induction of chlorophyll content in resistant maize inbred line, challenge inoculation with E. turcicum

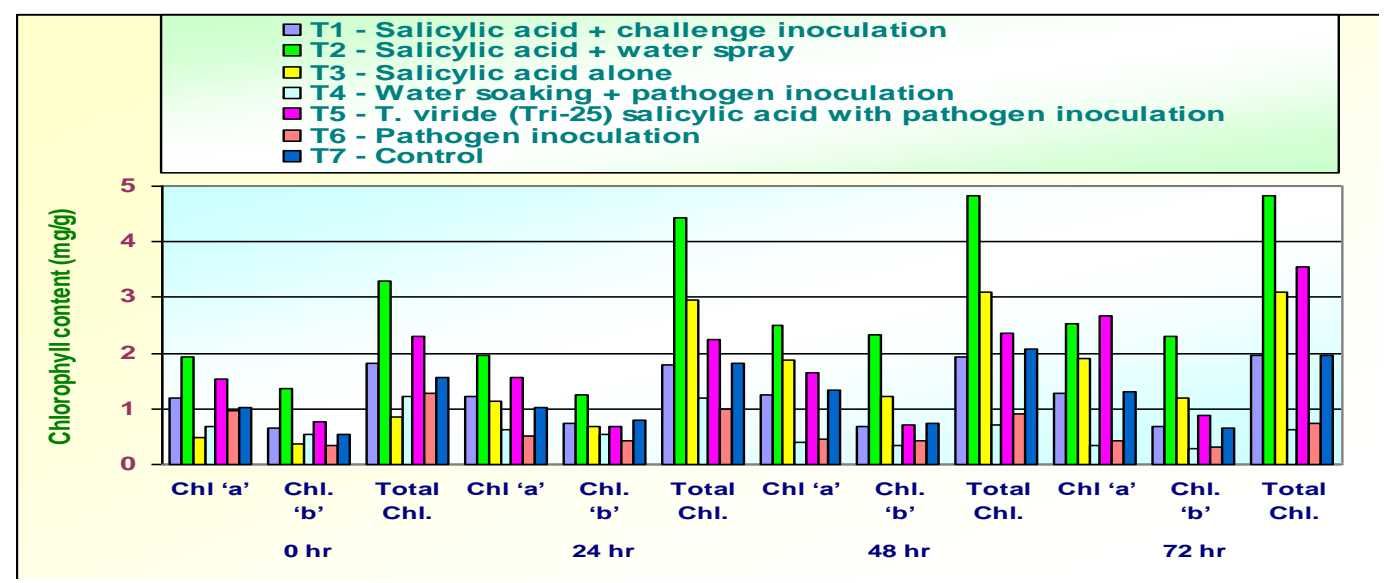

Fig.12 Effect of SAR inducing chemical on induction of chlorophyll content in susceptible maize inbred line, challenge inoculation with E. turcicum

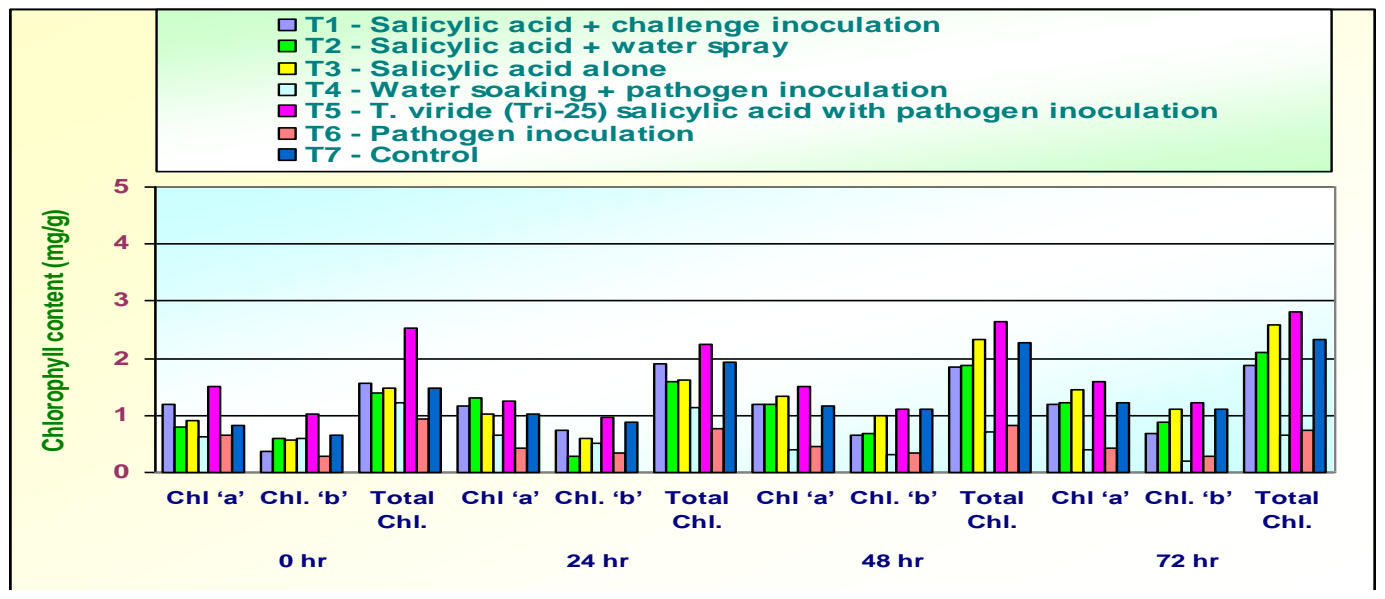


Similarly minimum content of total sugars were observed in resistant $(1.01 \mathrm{mg} / \mathrm{g})$ and susceptible $(0.51 \mathrm{mg} / \mathrm{g})$ in water soaking pathogen inoculation and salicylic acid challenge inoculation respectively at the initial sampling immediately after inoculation. At the end (72 hr) of sampling period, minimum content of total sugars were noticed in resistant $(1.09 \mathrm{mg} / \mathrm{g})$ and susceptible $(0.77$ $\mathrm{mg} / \mathrm{g}$ ) lines in pathogen inoculation treatment. However in salicylic acid alone treated both inbred lines showed increased total sugars content up to $24 \mathrm{hr}$. There after the concentration was decreased, but in both the inbred lines treated with salicylic acid - $T$. viride (Tri-25) with pathogen inoculation showed increased trend of total sugars upto 72 hr (Fig. 6).

The reducing sugars content showed that, the contents varied across the inbred lines and based on duration of crop growth. The maximum reducing sugars content was observed in salicylic acid alone at same day of inoculation in both resistant $(1.60 \mathrm{mg} / \mathrm{g})$ and susceptible $(1.14 \mathrm{mg} / \mathrm{g})$ inbred lines. At the end $72 \mathrm{hr}$ maximum reducing sugars (1.33 $\mathrm{mg} / \mathrm{g})$ and $(0.98 \mathrm{mg} / \mathrm{g})$ was found in resistant and susceptible lines respectively in salicylic acid - T. viride (Tri-25) with pathogen inoculation treatment. Least amount of reducing sugars were recorded in pathogen inoculation treatment at same day of inoculation in resistant $(0.50 \mathrm{mg} / \mathrm{g})$ and in susceptible $(0.23 \mathrm{mg} / \mathrm{g})$ inbred line with water soaking - pathogen inoculation treatment. Similarly at the end of $72 \mathrm{hr}$, least reducing sugars were noticed in resistant $(0.20 \mathrm{mg} / \mathrm{g})$ inbred line with pathogen inoculation alone treatment and $0.17 \mathrm{mg} / \mathrm{g}$ was found in salicylic acid alone treated susceptble inbred line (Fig. 8).

In case of non-reducing sugars, the contents were varied across the inbred lines. The maximum non reducing sugar content was showed in pathogen inoculation treatment at initial day of sampling in resistant (1.48 $\mathrm{mg} / \mathrm{g}$ ) and salicylic acid alone treatment in susceptible $(1.12 \mathrm{mg} / \mathrm{g})$ inbred lines. At the end $72 \mathrm{hr}$ of sampling, salicylic acid - water spray treatment was showed highest non reducing sugars $(1.21 \mathrm{mg} / \mathrm{g})$ in resistant inbred line, whereas salicylic acid alone treatment has showed highest non reducing sugars $(1.16 \mathrm{mg} / \mathrm{g})$ in susceptible inbred line. Least non reducing sugars content was noticed in salicylic acid - challenge inoculation treatment at initial sampling in resistant $(0.11 \mathrm{mg} / \mathrm{g})$ whereas in susceptible inbred line $0.25 \mathrm{mg} / \mathrm{g}$ was observed in susceptible inbred line. At $72 \mathrm{hr}$ after inoculation, non-reducing sugars were less in resistant $(0.59 \mathrm{mg} / \mathrm{g})$ in salicylic acid alone treatment and where as in susceptible line it was $0.48 \mathrm{mg} / \mathrm{g}$ in pathogen inoculation treatment (Fig. 8).

Among the two sugars, comparatively reducing sugars content was high in both the inbred lines. But, among the inbred lines resistant line having more reducing and nonreducing sugars compare to susceptible one. These results are in conformity with the reports of Jagadeesh (2013), Natheer et al., (2013) and Rashmi (2015) who found that the high level of sugars in the host plant are stated to be responsible for disease resistance. The levels of total sugar, non- reducing sugar and starch contents were less in infected leaves as compared to non-infected leaves (Sandeep et al., 2009).

\section{Chlorophyll content}

Chlorophyll is a vital pigment helps in photosynthesis and directly related to the productivity. Chlorophyll content decreased after infection and maximum decrease was found in susceptible inbred line compared to resistant inbred line (Fig. 9 and 10). Application of Trichoderma and salicylic acid 
as ISR and SAR which resulted in increase in chlorophyll content both in resistant and susceptible inbred line. The chlorophyll content was increased from the same day of inoculation upto $21^{\text {st }}$ day (ISR) and $72 \mathrm{hr}$ (SAR) of challenge inoculation the chlorophyll content was increased.

After the application of Trichoderma and salicylic acid, all types of chlorophyll 'a', 'b' and total chlorophyll content increased from $7^{\text {th }}$ day and $24 \mathrm{hr}$ of challenge inoculation in ISR and SAR respectively. Decreased trend was more in pathogen inoculation treatment without the Trichoderma and salicylic acid which was more in susceptible compared to resistant inbred line. All the chlorophyll components were maximum in resistant inbred line compared to susceptible and increased over a period of time in all the treatments except in pathogen inoculation treatment, where all the components slowly declined over a period of time. Both resistant and susceptible inbred lines treated with $T$. viride (Tri-25) - water spray treatment followed by $T$. viride (Tri-25) alone showed maximum concentration of all the chlorophyll contents compared to other treatments (Fig. 9 and 10). It has been observed that the total chlorophyll content increased three folds from initial sampling on the same day of inoculation to $24 \mathrm{hr}$ after inoculation $(0.85$ $\mathrm{mg} / \mathrm{g}$ and $2.95 \mathrm{mg} / \mathrm{g}$ ) in resistant inbred line treated with salicylic acid alone but it was not observed in susceptible line (Fig. 11 and 12).

Finally in SAR experiment, all the chlorophyll contents were maximum in resistant inbred line compared to susceptible inbred lines and increased from day of inoculation to $72 \mathrm{hr}$ after inoculation in all the treatments except in water soaking - pathogen inoculation and pathogen inoculation treatments. In pathogen inoculated treatments all the chlorophyll contents got reduced gradually from the day of inoculation to $72 \mathrm{hr}$ after inoculation (Fig. 11 and 12). Similar results of reduction of chlorophyll content after pathogen infection is evidenced by earlier workers (Amaresh, 2000, Mesta, 2006, Mandal et al., 2009 and Rashmi, 2015).

The study of disease resistance in maize plants treated with $T$. viride (Tri-25) and salicylic acid revealed the higher activity of defence related total phenols against maize turcicum leaf blight. Application of T. viride and salicylic acid in combination with each other significantly influenced the phenols activity.

Our results seems to be interesting, Trichoderma strains protect plants from pathogen attack by strengthening the epidermal and cortical cell walls using a deposition of callose, lignin and phenolics. Further, biocontrol strains stimulate the activities of defence enzymes and total phenols in plants that could be involved in synthesis of phytoalexins. Salicylic acid treated plants also showed an increase in total phenols and it was doubled at $24 \mathrm{hrs}$ after inoculation in resistant inbred line. The high phenols content in resistant inbred lines may be due to more sugar as it acts as precursor for synthesis of phenolics (Shyamala and Sivakumaar, 2012). Phenol content and its enhancement during disease progress was least in susceptible inbred line.

After pathogen inoculation without the ISR bioagent and SAR chemicals, the protein contents were increased from $24 \mathrm{hrs}$ to $72 \mathrm{hrs}$ and 7 day to $21^{\text {st }}$ day in all the treatments except in both the lines treated with water soaking - pathogen inoculation. The infection with pathogenic fungi, resulted in reduction of the total concentration of nitrogen in plant tissue.

Sugars are precursors for synthesis of phenols, phytoalexins, lignin and callose. 
Hence, they play an important role in defense mechanism of plants. Reviews on changes in sugar content during pathogenesis reveals that, Horsfall and Dimond (1957) assigned a major role for sugars in disease resistance. They classified the diseases as high sugar diseases and low sugar diseases. Infection by some pathogens bring about lot of changes in respiratory pathway and photosynthesis which are vital processes in plants. This lead to wide fluctuation in sugar contents (Farkas and Kiraly, 1962; Kuc, 1966 and Klement and Goodman, 1967). The intermediates of calvins reductive pentose (C3) pathway of $\mathrm{CO}_{2}$ fixation potentially can interconnect with other pathways of carbohydrate metabolism.

High amount of reducing sugar and nonreducing sugar content in resistant genotypes and less in susceptible genotypes could be either due to, i) Response of the host to infection resulting in increase in reducing sugar. ii) Part of that may be utilized by the pathogen. iii) Interference by the pathogen in the amylolytic activity (Jagadeesh, 2013).

On the same day of challenge inoculation even phenol, protein, sugar and chlorophyll contents were low. Therefore, the biochemical contents increased on $7^{\text {th }}$ day and $24 \mathrm{hrs}$ after challenge inoculation in ISR agent and SAR chemical treated plants. Activity of biochemical contents decreased as the day passes in the pathogen inoculation treatment without ISR and SAR treatments.

It is possible that $T$. viride (Tri-25) and salicylic acid application mediated induction of defence resposes could play a significant role in reducing turcicum leaf blight of maize under pot conditions, resulting in improved photosynthetic efficiency in host plants. Likewise, the study by Tanwar et al., (2013) demonstrated that the chlorophyll content got increased significantly in combined inoculation.

\section{Acknowledgement}

The authors are thankful to University of Agricultural Sciences, Raichur department of plant pathology for providing a necessary facilities to carry out this work.

\section{References}

Arjunan, A., Vidhyasekaran, D. and Kandaswamy, T. K., 1976, Changes in aminoacids and amides content in jowar leaves infected with Helminthosporium turcicum. Curr. Sci., 45: 229 - 230.

Bisen, K., Biswas, S. K., Virendra Kumar, Krishna Lal, Rakesh kumar and Nand Kumar, 2015, Biochemical changes in relation to brown leaf spot (drechslera oryzae) resistance in different rice genotypes. J. Pl. Studies, 4(2): 81-91.

Bray, H. G. and Thorpe, W. Y., 1954, Analysis of phenolic compounds of interest in metabolism. pp. 27. In: Moth. Biochem Annal (Ed.) GLICK. D. Intersarnae Publishing Inc., New York.

Farkas, G. L. and Kiraly, Z., 1962, Role of phenolic compounds in the physiology of plant diseases and disease resistance. Phytopathol, 44: 105 - 150.

Harlapur, S. I., Wali, M. C., Anahosur, K. H. and Muralikrishna, S., 2000, A report on survey and surveillance of maize diseases in Northern Karnataka. Karnataka J. Agric. Sci., 13: 750-751.

Horsfall, J. G. and Dimond, A. E, 1957, Interactions of tissue sugar, growth substances and disease susceptibility. $Z$. Pflanzekrankh. Pflenzenschutz., 64: 415-421.

Jagadeesh, 2013, Studies on biochemical basis and resistance sources of maize to turcicum leaf blight caused by Exserohilum turcicum (Pass.) Leonard and Suggs. M.Sc. (Agri.) Thesis, Univ. Agric. Sci, Bangalore, Karnataka (India). 
Kuc, J., 1966, Resistance of plants to infectious agents. Ann. Rev. Microbiol., 20: 337-370.

Lowry, O. H., Rosebrough, Fan, A. L. and Randall, R. J., 1951, Protein measurement with folin phenol reagent. J. Biol. Chem., 193: 265- 275.

Nagaveni, T., 2005, Resistance factors for leaf blight of barley caused by Helminthosporium sativum Pam., King and Bakke. M. Sc. (Agri.) Thesis, Univ. Agric. Sci, Dharwad, Karnataka (India).

Natheer, S. E., Sekar, C. and Amutharaj, P., 2013, Positive role of intergeneric microbial Co-aggregates, comprising of Pseudomonas and Paenibacillus cells, on the enhancement of induced systemic resistance (ISR) in maize Helminthosporium turcicum pathosystem under semiarid condition. International J. Pharm. Bio. Sci., 4(2): $82-830$.

Nelson, N., 1944, A photometric adaptation of the Somogy's method for determination of glucose. J. Biol. Chem., 153: 375-380.

Pandurangegowda, K. T., 1991, Host resistance, loss assessment and management of Exserohilum turcicum (Pass) Leonard and Suggs. leaf blight of maize. Ph.D. Thesis, University of Mysore.
Pradeepkumar, M., 2005, Physiology and biochemical basis of resistance to leaf blight of Barley (Hordeum vulgare L.). M. Sc. (Agri.) Thesis, Univ. Agric. Sci., Dharwad, Karnataka (India).

Rashmi, R., 2015, Epidemiology and disease resistance in maize against turcicum leaf blight (Exserohilum turcicum). M.Sc. (Agri.) Thesis, Univ. Agric. Sci., Raichur, Karnataka, 5-40.

Sandeep, S., Asthir, B., Navtej, S., B. and Satwinder, K. M., 2009, Induction of carbohydrate metabolism in relation to leaf blight in Barley (Hordeum vulgare). Adv. Biol. Res., 3(3-4): 61-66.

Shyamala, L. and Sivakumar, P. K., 2012, Integrated control of blast disease of rice using the antagonistic rhizobacteria Pseudomonas fluorescens and the resistance inducing chemical salicylic acid, International J. Res. pure and Appl. Microbio., 2(4): 59-63.

Sriram, S., Manasa, S. B. and Savitha, M. J., 2009, Potential use of elicitors from Trichoderma in induced systemic resistance for the management of Phytophthora capsici in red pepper. J. Biol. Control., 23(4): 449-456.

Staples, R., C. and Stahmann, M. A., 1964, Changes in protein and several enzymes in susceptible leaves after infection by bean rust fungus. Phytopathol., 54: $760-764$.

\section{How to cite this article:}

Geeta, D.S. Aswathanarayana, M.K. Naik, Mallikarjun Kenganal, Prakash H. Kuchanur and Beladadi, R.V. 2018. Positive Role of Salicylic Acid and Trichoderma on the Enhancement of Systemic Acquired Resistance (SAR) and Induced Systemic Resistance (ISR) in Maize Exserohilum turcicum Pathosystem under Greenhouse Condition. Int.J.Curr.Microbiol.App.Sci. 7(10): 1509-1522. doi: https://doi.org/10.20546/ijcmas.2018.710.169 